\title{
Information Technology Service Management [ITSM] Research: A Literature Review of Practices, Solutions and Measurement
}

\author{
Vipul Jain ${ }^{1}$, O. P. Wali ${ }^{2}$ and V. Raveendra Saradhi ${ }^{3}$ \\ ${ }^{1}$ Ph.D Scholar, ${ }^{2}$ Professor, ${ }^{3}$ Associate Professor, Indian Institute of Foreign Trade, New Delhi, India \\ E-mail: vipul_phd12@iift.edu, opwali@iift.edu and rsaradhi@iift.edu
}

\begin{abstract}
This is a systematic literature review to understand the adopted practices, proposed solutions and measurement models for Information Technology Service Management [ITSM] approaches. This paper extends the existing research and past literature reviews in this area by including recent published research from 2010 to 2018 . The review finds that ITSM practices are not uniformly adopted, and some processes tend to be adopted more widely than others. The review also finds many measurement models that are either not validated, or only partially validated, and sees a gap between academic research and practitioner community, who are the primary intended users of these models and frameworks. There are proposed solutions for ITSM integration with other management systems that can benefit from further research for validation. We recommend future researchers to collaborate with practitioners, so that proposed models and frameworks can be incorporated into the relevant standards, where feasible.
\end{abstract}

Keywords: IT Service Management, IT process maturity, ITIL, ITSM

\section{INTRODUCTION}

This paper reviews the available research in the area of Information Technology Service Management [ITSM]. ITSM approach and its associated frameworks are widely used by practitioners for managing delivery of Information Technology [IT] services. There are significant investments made by organizations worldwide in implementing and adopting ITSM approaches and frameworks.

We review the existing research with a focus on understanding three aspects of ITSM. One, we look for practices followed by the organizations that have adopted ITSM approaches. Two, we explore the proposed solutions to the problems faced by practitioners. Finally, we review the existing research for models, tools or frameworks developed for measurement or assessment of ITSM aspects. The review also identifies the areas that can benefit from further academic research.

The findings of this review are useful in many significant ways for practitioners as well as academics. First, it augments the existing body of knowledge in ITSM. This work extends the findings of past literature reviews in this area, and adds the latest research to it. Second, it provides useful insights from academic research to the IT practitioner community. IT managers and leaders responsible for planning and implementing ITSM approaches can use these finding as an aid to decision-making. IT managers and leaders in organizations, where implementation projects are complete, can use these findings for understanding and resolving ongoing operational issues and challenges. Finally, it adds to the process of building a "research tradition" in the relatively recent area of ITSM research by linking the existing research, identifying gaps therein, and providing useful pointers to future researchers.

The rest of this paper is structured as follows. First, a background to ITSM is provided for understanding the context of this review. Next, the scope of this review is explained along with the objectives. In the next section, the review approach is explained, followed by the actual process of conducting the review. Next section discusses the findings from the selected research. Lastly, we analyze the findings from the existing research and identify the areas of further research.

\section{INFORMATION TECHNOLOGY SERVICE MANAGEMENT}

The disciplines of IT Governance and IT Service Management [ITSM] emerged from the need for innovation in practices as the nature of IT organizations changed from technology providers to service providers. The boundaries between the applicability of these terms are rather fluid, but broadly, IT governance has a strategic view of aligning IT to business, whereas ITSM addresses design, provisioning and ongoing delivery of IT services. It is a subset of the Services Science discipline that focuses on IT operations delivery and support (Galup, Quan, Dattero, \& Conger, 2007).

ITSM can be defined as an approach to IT operations that is characterized by its emphasis on IT services, customers, service level agreements, and an IT function's handling of its daily activities through processes [(Conger, Winniford, \& Erickson-Harris, 2008); (Marrone \& Kolbe, 2011)]. There are many available frameworks or models for implementing an ITSM in practice. The most common one is the IT Infrastructure library [ITIL] which has evolved into a de facto standard for IT service providers [(Iden \& Eikebrokk, 2013)]. The current version of ITIL, Version 3, was published in May 2007, and revised in 2011. It consists of 26 sections which are included in five services: Service Strategy, Service Design, Service Transition, Service Operation and Continual Service Improvement. 
There is available evidence that ITSM is widely used in practice today, in its different forms (Cots, Casadesús, \& Marimon, 2014; Marrone, Gacenga, Cater-Steel, \& Kolbe, 2014; Marrone \& Kolbe, 2011b). Although the exact number of organizations adopting ITSM approaches is not known, there are many indicators of their growing awareness and adoption. For example, there are now fifty national chapters of the ITSM Forum [itSMF], with 6000 member-organizations and an excess of 40,000 individual members worldwide. Over 500 organizations in at least forty countries are now certified on the international standard for ITSM, which is based on ITIL (Marrone et al., 2014).

While the adoption of these practices is widespread, it is still a relatively new area for academic research (Galup et al., 2007). Lack of available research was initially coupled with optimistic claims about its perceived benefits, backed by little evidence, e.g. claims of up to forty-eight percent cost reduction by applying ITSM principles (Galup, Dattero, Quan, \& Conger, 2009). The promises of ITSM, and its adoption by the practitioner community were followed by an increase in the academic research interest after 2005 (Shahsavarani \& Ji, 2014).

\section{METHOD AND SCOPE}

This systematic literature review follows the guidelines from existing literature in its scope, method and analysis [(Webster \& Watson, 2002); (Kitchenham, 2007); (Okoli \& Schabram, 2010); (Levy \& Ellis, 2006)]. As per the classification by Okoli \& Schabram (2010), this is a standalone literature review, which is " $a$ journal-length article whose sole purpose is to review the literature in a field, without any primary data (that is, new or original) collected or analyzed” (Okoli \& Schabram, 2010).

\section{A. Review Scope}

We limit the scope of this review to findings from academic research published between 2010 and April 2018. Research and reports published in the practitioner and industry community are out of the scope for this review. However, if the existing academic research makes references to data available in such publications, it is reviewed. The research published prior to 2010 is not included in this review for two reasons. First, we rely on existing literature reviews that cover the past research, so that we can build and extend on them, instead of duplicating their efforts. Second, the practices of IT Service Management are changing along with changes in IT services and technologies. We set this timeline scope to capture the state-of-the-art in research findings.

\section{B. Search process}

Since the area of interest is ITSM, the search is conducted on ITSM and its variant keywords. ITIL, being a leading ITSM standard and its variant keywords are also included. Following keywords are searched.
1. "IT Service management"

2. ITSM

3. ITIL

4. "IT Infrastructure library"

5. "Information Technology Infrastructure Library"

6. "Information Technology Service Management"

The search is conducted in the leading academic databases of EBSCO, Emerald and Science Direct for the period January 2010 to April 2018. The keywords are searched in article titles, abstracts and author-supplied keywords.

The results are reviewed for inclusion as per the defined criteria. A forward and backward reference search is done on the selected results and the inclusion and exclusion criteria applied again to get the final set of articles.

\section{Inclusion and exclusion}

These are the inclusion criteria used for selecting the articles:

1. Only peer-reviewed Journal articles conference papers;

2. Publications only in English language;

3. Artifacts that are within the scope of this review i.e. Research on ITSM practices; measurement and assessment models; and solutions ;

4. Content that is accessible online over Internet;

5. ITSM articles that deal with post-implementation challenges and outcomes.

These are the exclusion criteria used for rejecting the articles:

1. Descriptive articles or papers that are explanatory in nature;

2. Articles published prior to the year 2010;

3. Articles on ITSM that deal with implementation challenges and critical success factors;

4. Articles on ITSM that deal with benefits and consequences.

\section{Search Results}

The search process as per the defined criteria resulted in an initial list of ninety-three papers and journal articles. After applying the inclusion and exclusion criteria, we eliminated twenty-two articles for their research outcome. These were papers with descriptive content with no original research findings. Of the remaining articles, forty-seven were eliminated being out of scope for our review due to the topic addressed in their research. Finally, one duplicate study was eliminated to get the final set of twenty-three research articles. Out of these, nineteen are journal articles and four are conference papers. Table A in the Appendix provides a list of the selected papers. 


\section{LITERATURE REVIEW FINDINGS}

\section{A. Classification}

The results are classified, as per Vessey et al., (Vessey, Ramesh, \& Glass, 2002), who created a classification system for Information Systems research, by encompassing the related disciplines of computer science, software engineering and IS. The classification is done on two dimensions of the level of analysis, and the research methods. The level of analysis is classified into one of these categories. The categories of "Computer System" and "Computer Element" are modified to "IT System" and "Process" respectively to adapt to the IT Services context.

1. Society

2. Profession

3. Interorganizational context

4. Organizational context

5. Project

6. Group

7. Individual

8. Abstract concept

9. IT system

10. Process

The research methods are classified into one of these categories. Vessey et al (2002) had a few more items, that are excluded to make this list relevant to the IT services context.

1. Conceptual analysis

2. Case study

3. Grounded theory - Characterizes a paper that uses an inductive approach to develop theory

4. Literature review

5. Survey

6. Instrument development

7. Experiment (human subjects)

8. Concept implementation (proof of concept) Characterizes a paper that develops a system to demonstrate feasibility of a proposed idea

We added a category of "multi-method" for studies that use a combination of two or more of these methods.

\section{Level of analysis}

The Table 1 summarizes the classification for the level of analysis. From this, we can see that research has been conducted both at an aggregate level of analysis covering organization or IT systems, as well as at the process level. There is limited research conducted at the group and interorganizational level.

\section{Research Methods}

Table II lists the research methods employed in the reviewed studies. A majority of the research is conceptual, where either a theoretical model or an instrument is developed, and in some cases tested in a limited context.
Empirical research in this area is limited, and there is only one study that employs survey-based empirical research.

TABLE I LEVEL OF ANALYSIS

\begin{tabular}{|l|c|}
\hline \multicolumn{1}{|c|}{ Level } & Count \\
\hline Group & 1 \\
\hline Interorganizational Context & 1 \\
\hline IT Process & 6 \\
\hline IT System & 3 \\
\hline Organizational Context & 5 \\
\hline Profession & 5 \\
\hline Project & 2 \\
\hline
\end{tabular}

TABLE II RESEARCH METHOD
\begin{tabular}{|l|c|}
\hline \multicolumn{1}{|c|}{ Research Method } & Count \\
\hline Case Study & 2 \\
\hline Grounded Theory & 5 \\
\hline Instrument Development & 6 \\
\hline Literature Review & 4 \\
\hline Multi method & 5 \\
\hline Survey & 1 \\
\hline
\end{tabular}

\section{B. Chronology and Sources}

TABLE III YEAR-WISE PUBLICATION DETAILS

\begin{tabular}{|c|c|}
\hline Year & Count of Publications \\
\hline 2010 & 2 \\
\hline 2011 & 1 \\
\hline 2012 & 6 \\
\hline 2013 & 1 \\
\hline 2014 & 5 \\
\hline 2015 & 2 \\
\hline 2017 & 3 \\
\hline 2018 & 3 \\
\hline
\end{tabular}

Tables III and IV provide year-wise and source-wise details of the publications respectively. This field has been active for researchers, with publications every year in the search period, except for one year. The publication details show us that the research is widely dispersed across publications, with no publication accounting for more than three articles.

\section{Geography of Research}

Table $\mathrm{V}$ provides details on the nationalities of the authors active in this area. Overall, European authors lead in this area (11 studies), followed by Australian authors (7 studies). All the other major regions of the world are represented by the authorship, and the research interest seems to be globally widespread, though biased towards Europe and Australia. 
TABLE IV PUBLICATION DETAILS

$\left.\begin{array}{|l|c|}\hline \multicolumn{1}{|c|}{\text { Publication }} & \text { Count } \\ \hline \text { Benchmarking: An International Journal } & 1 \\ \hline \begin{array}{l}\text { Communications of the Association for Information } \\ \text { Systems }\end{array} & 2 \\ \hline \text { Computer Standards \& Interfaces } & 1 \\ \hline \text { Computers in Human Behavior } & 1 \\ \hline \text { Decision Support Systems } & 1 \\ \hline \text { Electronic Journal of Business Research Methods } & 1 \\ \hline \begin{array}{l}\text { European Conference on Software Process } \\ \text { Improvement }\end{array} & 1 \\ \hline \text { IEEE Transactions on Systems, Man \& Cybernetics } & 1 \\ \hline \text { Information \& Management } & 2 \\ \hline \text { Information \& Software Technology } & 1 \\ \hline \text { Information Systems Management } & 1 \\ \hline \begin{array}{l}\text { International Conference on Service-Oriented } \\ \text { Computing }\end{array} & 1 \\ \hline \text { International Journal of Information Management } & 1 \\ \hline \begin{array}{l}\text { Journal of Information Technology Theory and } \\ \text { Application }\end{array} & 1 \\ \hline \text { Journal of Knowledge Management } & 1 \\ \hline \text { Knowledge-Based Systems } & 1 \\ \hline \text { Kybernetes } & 1 \\ \hline \text { Proceedings of the Annual Conference of the } \\ \hline \text { Wirtschaftsinformatik Proceedings }\end{array}\right)$

\section{Research Findings}

The findings are presented in two parts. First, we summarize the findings from the past literature reviews, followed by the literature review conducted by us.

\section{Previous Literature Review Findings}

Iden and Eikebrokk (Iden \& Eikebrokk, 2013)found seven independent studies on ITSM implementation status, published between 2008 and 2011. The findings support wide-spread ITSM adoption and interest, with majority of the surveyed organizations having either adopted, or planning to adopt ITSM. None of the studies, however, report on the implementation status at a process level, and treat the ITSM as a single variable. There are two studies, with contradictory outcomes, on the adoption differences between service support and service delivery processes. One study found a preference for service support processes over service delivery processes in the implementation priority, whereas the other study had a divergent outcome. Therefore, it remains inconclusive if organizations are adopting some specific processes over others, or whether there is in fact, a preference to pick some processes over others. This is also identified as an area of further research by Iden \& Eikebrokk (Iden \& Eikebrokk, 2013).
TABLE V AUTHOR COUNTRY OF AFFILIATION

\begin{tabular}{|l|c|}
\hline \multicolumn{1}{|c|}{ Country of Author } & Count of Publications \\
\hline Australia & 7 \\
\hline Brazil & 1 \\
\hline Canada & 1 \\
\hline Chile & 1 \\
\hline Denmark & 2 \\
\hline Germany & 1 \\
\hline Iran & 1 \\
\hline Norway & 1 \\
\hline Portugal & 1 \\
\hline Saudi Arabia & 1 \\
\hline South Africa & 1 \\
\hline Spain & 5 \\
\hline Switzerland & 1 \\
\hline UK & 1 \\
\hline USA & 2 \\
\hline
\end{tabular}

Mesquida et al., (Mesquida, Mas, Amengual, \& CalvoManzano, 2012) reviewed twenty-eight primary studies between 1998 and 2011 to identify process assessment frameworks or models that use ISO/IEC 15504 standard for ITSM process assessments. ISO/IEC 15504 standard was used (it is superseded by a new standard from 2015) for Software Process Improvements (SPI), and the objective of the review was to find a solution to integrate the disciplines of SPI and ITSM process assessment and improvements using a common framework. They found nine models, seven out of which used approaches based on or compatible with ISO/IEC 15504.

Marrone \& Hammerle (Marrone \& Hammerle, 2017) did a keyword analysis on both academic and practitioner literature between the periods of 1 Jan 2000 and 1 May 2016, to identify gaps between practitioner needs and current ITSM academic research and use these to build a research agenda for academics. For the scope of our review, the key findings from this review are 1) Practitioners seek to implement multiple frameworks in their organizations, while much of ITSM research is focused towards implementing one framework at a time; 2) Practitioners look for help in managing IT infrastructures using ITSM, while academic research has largely ignored this area so far; and 3) Academic research is limited on the role played by ITSM software tools.

Findings from existing literature reviews can be summarized thus - 1) ITSM frameworks are widely adopted and popular with IT managers; 2) Most research on adoption is at the system level, and there are no studies at the process level adoption; 3 ) There is limited evidence that some processes may be preferred over others; 4) There are many process assessment models available, some of which 
are based on ISO/IEC 15504; and 5) There are gaps between practitioner needs and academic research in terms of adopting multiple frameworks simultaneously, software ITSM tools, and focus on IT Infrastructure.

\section{Current Literature Review Findings}

From the articles reviewed by us, the findings can be broadly categorized into 1) State of ITSM implementations and practices; 2) Assessment and measurement models and 3) Suggested solutions.

\section{a. ITSM Practices:}

There are three studies on the state of ITSM implementations and practices. Marrone et al., (Marrone, Gacenga, Cater-Steel, \& Kolbe, 2014) use Institutional Theory to build an understanding of the mechanism by which adoption differences may arise in organizations, and test it empirically. As per the theory, the structure and actions of an organization are significantly impacted by the institutional environment in which it is situated. In an extensive empirical study of more than six hundred respondents across the USA, UK and continental Europe, their research explores adoption variations within ITIL processes, and study the contribution of factors such as country, size, and industry sector towards these variations. They find that operational level ITIL processes are deployed more widely than tactical/strategic processes. They also find strong evidence that adoption of ITIL processes varies at a country level, but there is only partial evidence of variations by organization size and industry sector. In terms of Institutional Theory, there is some evidence that all three influences as per the theory - coercive, mimetic, and normative - may play a role when organizations adopt ITSM frameworks. The adoption of operational-level processes is performed by a cohesive workgroup in the IT organisation, while tactical/strategic processes require the coordination of various divisions in the organisation. Because of ease of implementation, IT managers may decide to focus on processes considered internal to them first.

In a case study, Muller and de Lichtenberg (Müller \& de Lichtenberg, 2018) use Organizational Culture Text Analysis Tool (OCTAT) to compare culture profile of ITIL with the culture profile of an IT organization. The two profiles are found to be clearly distinct and incongruent. In the long term, this may inhibit organization performance. This augments the findings of earlier research that the organizational culture and ITSM processes influence each other. In another case study, Trusson et al., (Trusson, Hislop, \& Doherty, 2017) test the "knowledge hoarding" in information workers and found that IT service professionals are inclined to share knowledge as a regular practice. They suggest that "the characterization of such workers as 'knowledge hoarders' is an unreliable myth created via rhetorical discourse rather than reliable truth founded on convincing empirical evidence. This has implications for management practice; specifically, we argue, that managerial 'best practices' such as ITIL that peddle this rhetorical myth should be amended".

\section{b. Assessment and Measurement}

There are eight studies reviewed that deal with measurement and assessment of ITSM, including a literature review on process assessment frameworks (Walker, McBride, Basson, \& Oakley, 2012). Table 8 summarizes the findings from the other seven studies. Except for one model that applies to service provider capability assessment, the remaining ones are either process or performance measurement frameworks.

TABLE VI SUMMARY OF ITSM ASSESSMENT AND MEASUREMENT STUDIES

\begin{tabular}{|l|l|}
\hline \multicolumn{1}{|c|}{ Study } & \multicolumn{1}{c|}{ Contribution } \\
\hline $\begin{array}{l}\text { (Gacenga, Cater-steel, Toleman, \& Tan, } \\
\text { 2012) }\end{array}$ & ITSM Performance Management Framework [PMF]; Failed validation testing \\
\hline $\begin{array}{l}\text { (Bin-Abbas \& Bakry, 2014) } \\
\text { 2018) }\end{array}$ & An IT Governance Assessment Tool with 50 controls; Needs validation \\
\hline (McNaughton, Ray, \& Lewis, 2010) & A Software-mediated Process Assessment Model and Instrument; Limited validation \\
\hline (Walker et al., 2012) & ITSM Performance Measurement Framework; Partial validation \\
\hline (Wulf, Winkler, \& Brenner, 2015) & $\begin{array}{l}\text { A 26-item ITSM Capability Measurement Framework to assess service providers; } \\
\text { Validated }\end{array}$ \\
\hline (Machado, Reinehr, \& Malucelli, 2012) & $\begin{array}{l}\text { ITSM Maturity Model for Small \& Medium Enterprises [called MM-GSTI; Limited } \\
\text { validation }\end{array}$ \\
\hline
\end{tabular}

\section{Solutions}

There are nine studies that propose a solution to existing implementation or management challenges for ITSM. Table 9 summarizes these studies. These are broadly in the following areas - 1) Solutions to the problems and challenges of a common discourse while discussing ITSM. Two of these studies propose ontologies and one proposes a metamodel; 2) Decision making aids to select the right tools or processes; and 3) Integration of ITSM with other management systems. 
TABLE VII SUMMARY OF ITSM SOLUTIONS

\begin{tabular}{|l|l|}
\hline \multicolumn{1}{|c|}{ Study } & \multicolumn{1}{c|}{ Contribution } \\
\hline (Galup \& Dattero, 2010) & $\begin{array}{l}\text { Proposed a method to tune ITSM processes to ensure Persons, Roles, and Knowledge are properly } \\
\text { aligned for successful process operations }\end{array}$ \\
\hline $\begin{array}{l}\text { (M. C. Valiente, Garcia- } \\
\text { Barriocanal, \& Sicilia, 2012) }\end{array}$ & Proposed Onto-ITIL Ontology \\
\hline $\begin{array}{l}\text { (M.-C. Valiente, García- } \\
\text { Barriocanal, \& Sicilia, 2012) }\end{array}$ & Developed an Ontology model to integrate Software Engineering with ITSM \\
\hline (Rouhani, 2017) & $\begin{array}{l}\text { Developed a Superiority and Inferiority [SIR] ranking multi-criteria decision making [MCDM] model } \\
\text { with 46 criteria for ITSM software selection }\end{array}$ \\
\hline (Shrestha et al, 2014) & Proposed a method to select the right candidate processes for improvement \\
\hline (Orta et al, 2014) & Developed and tested a simulation model to aid decision-making in ITSM environments \\
\hline (Mesquida \& Mas, 2015) & $\begin{array}{l}\text { Review the existence of standards for the integration of management systems; Evaluate existing } \\
\text { initiatives for creation of an IMS that integrates the ISO 9001:2008 QMS and the ITSM }\end{array}$ \\
\hline $\begin{array}{l}\text { (Gama, Vicente, \& da Silva, } \\
\text { 2014) }\end{array}$ & Proposed an ITIL Metamodel for uniformly describing and discussing ITIL concepts \\
\hline (Orta \& Ruiz, 2018) & $\begin{array}{l}\text { Proposed ITSM implementation method based on business process management \& simulation } \\
\text { modelling }\end{array}$ \\
\hline
\end{tabular}

\section{DISCUSSION}

Aggregating the past literature reviews with this review, we see that there are some additional insights in the recent research. We discuss in detail the three reviewed areas of practices, measurement and solutions, and suggest some areas for further research.

\section{A. ITSM Practices}

The prior literature reviews found some evidence that organizations may be adopting ITSM processes differently. In the current review, there is evidence that operational processes are deployed more widely than other processes. There is also an explanation using Institutional Theory about the causes for the same. The finding has important implications for IT managers and practitioners. If organizations are successfully adopting only certain processes, organizations can review their plans and investments on ITSM to target areas of maximum benefit. Since the available study uses datasets from North America and Europe, we believe this can be an area for further research, by replicating similar studies in different geographical contexts where ITSM is widely used, e.g. India and China. It will also be worthwhile to compare the performance of organizations that have only partially adopted ITSM with the ones that have adopted all processes. There is also evidence that ITSM may cause a cultural incongruence or conflict, through imposing some assumptions and practices divergent from the actual behaviors. Understanding these relationships at a process level will help organizations plan and prepare to deal with these challenges successfully.

\section{B. Assessment and Measurement}

There is a lot of published research in this area. Including the literature review, there are more than fifteen studies available that propose an assessment model for the overall IT system or for the individual processes. The volume of studies, however, do not seem to be building into a cohesive body of research. We observe some features of the research in this area. First, most of these models are built by a combination of synthesis of available standards or frameworks and interviews with experts. There is a lack of theoretical grounding for most of these instruments and tools. Secondly, there is limited validation of these models in practice. In many cases, the models undergo some testing for instrument validity, but are not adopted by later researchers. Third, these models are intended for practitioner use, but we could not find evidence for their adoption by IT managers from the available research.

IT practitioners look to frameworks and standards for adoption. For research in this area to make an impact, we suggest a closer collaboration between academic research and practitioner community, so that the findings could be used to modify and enhance the ITSM standards. IT managers are more likely to adopt tools and instruments that have sanction of a wider community. This is also in line with the mimetic impact of ITSM adoption identified by Marrone et al., (Marrone et al., 2014). Finally, most studies are point in time studies. Therefore, there is limited understanding of how ITSM practices evolve, and when. We could find only one study of the impact over a time interval. We believe all ITSM research areas can benefit from similar study approaches.

\section{Solutions}

In prior literature reviews, two identified research gaps are integration of ITSM with other frameworks, and studies on ITSM software. We see both have benefitted from recent academic research. The studies on Ontologies and Metamodel are mainly targeted towards a common language for ITSM, and there are proposed frameworks for integration of different management systems. There is an available study on selection of the right software for ITSM implementation. We suggest future researchers develop the suggested solutions in current studies into usable tools or instruments and validate them with empirical data or case studies. 


\section{CONCLUSION}

In this paper, we review the current state of research on ITSM practices, solutions and measurement models. We enrich the current body of knowledge in this area in three significant ways. First, we extend the currently available literature reviews in terms of coverage to the latest time period. Second, we find valuable gaps in the current state of academic research and suggest areas for future research that can benefit practitioner community. Third, we find that ITSM is adopted differently at an individual process level, and there are some cultural challenges introduced by ITSM processes.

\section{Appendix: List of Selected Artifacts for Literature Review}

\begin{tabular}{|c|c|}
\hline Title & Reference \\
\hline A Five-Step Method to Tune Your ITSM Processes & (Galup \& Dattero, 2010) \\
\hline $\begin{array}{l}\text { A fuzzy superiority and inferiority ranking based approach for IT service management } \\
\text { software selection }\end{array}$ & (Rouhani, 2017) \\
\hline A Method to Select IT Service Management Processes for Improvement & $\begin{array}{l}\text { (Shrestha, Cater-Steel, Toleman, \& } \\
\text { Tan, 2014) }\end{array}$ \\
\hline A Proposal and Evaluation of a Design Method in Design Science Research & (Gacenga et al., 2012) \\
\hline Applying an ontology approach to IT service management for business-IT integration & (M. C. Valiente et al., 2012) \\
\hline $\begin{array}{l}\text { Applying Ontology-Based Models for Supporting Integrated Software Development and } \\
\text { IT Service Management Processes }\end{array}$ & (M.-C. Valiente et al., 2012) \\
\hline Assessment of IT governance in organizations: A simple integrated approach & (Bin-Abbas \& Bakry, 2014) \\
\hline $\begin{array}{l}\text { Benefits and relevance of International Standards in a design science research project for } \\
\text { process assessments }\end{array}$ & (Shrestha et al., 2018) \\
\hline Decision-making in IT service management: a simulation based approach & (Orta et al., 2014) \\
\hline Designing an evaluation framework for IT service management & (McNaughton et al., 2010) \\
\hline Implementing IT Service Management: A systematic literature review & (Iden \& Eikebrokk, 2013) \\
\hline $\begin{array}{l}\text { Integrating IT service management requirements into the organizational management } \\
\text { system }\end{array}$ & (Mesquida \& Mas, 2015) \\
\hline ISO/IEC 15504 measurement applied to COBIT process maturity & (Walker et al., 2012) \\
\hline $\begin{array}{l}\text { IT Service Management Process Improvement based on ISO/IEC 15504: A systematic } \\
\text { review }\end{array}$ & (Mesquida et al., 2012) \\
\hline IT Service Management: A Cross-national Study of ITIL Adoption & (Marrone et al., 2014) \\
\hline ITIL Metamodel & (Gama et al., 2014) \\
\hline $\begin{array}{l}\text { Measuring IT Service Management Capability: Scale Development and Empirical } \\
\text { Validation }\end{array}$ & (Wulf et al., 2015) \\
\hline Met4ITIL: A process management and simulation-based method for implementing ITIL & (Orta \& Ruiz, 2018) \\
\hline $\begin{array}{l}\text { Relevant Research Areas in IT Service Management: An Examination of Academic and } \\
\text { Practitioner Literatures }\end{array}$ & (Marrone \& Hammerle, 2017) \\
\hline $\begin{array}{l}\text { Research In Information Technology Service Management (ITSM) (2000-2010) - An } \\
\text { Overview }\end{array}$ & (Shahsavarani \& Ji, 2014) \\
\hline The culture of ITIL: Values and implementation challenges & (Müller \& de Lichtenberg, 2018) \\
\hline The rhetoric of "knowledge hoarding": a research-based critique & (Trusson et al., 2017) \\
\hline $\begin{array}{l}\text { Towards a Maturity Model for IT Service Management Applied to Small and Medium } \\
\text { Enterprises }\end{array}$ & (Machado et al., 2012) \\
\hline
\end{tabular}

\section{REFERENCES}

[1] H. Bin-Abbas and S. H. Bakry, "Assessment of IT governance in organizations: A simple integrated approach", Computers in Human Behavior, Vol. 32, pp. 261-267, 2014. [Online]. Available: https://doi.org/10.1016/j.chb.2013.12.019.

[2] S. Conger, M. Winniford and L. Erickson-Harris, "Service Management in Operations", in American Conference on Information Systems, pp. 1-11, 2008.

[3] S. Cots, M. Casadesús and F. Marimon, "Benefits of Implementing Service management Standard ISO 20000", Proceedings of the 1st Int. Conf. on Quality Engineering and Management, pp. 3-14, 2014.

[4] F. Gacenga, A. Cater-steel, M. Toleman and W. Tan, "A Proposal and Evaluation of a Design Method in Design Science Research”, The
Electronic Journal of Business Research Methods, Vol. 10, No. 2, pp. 89-100, 2012. Retrieved from www.ejbrm.com

[5] S. D. Galup and R. Dattero, "A Five-Step Method to Tune Your ITSM Processes", Information Systems Management, Vol. 27, No. 2, pp. 156-167, $2010 . \quad$ [Online]. Available: https://doi.org/10.1080/10580531003685220.

[6] S. D. Galup, R. Dattero, J. J. Quan and S. Conger, "An overview of IT service management”, Communications of the ACM, Vol. 52, No. 5, pp. $124, \quad 2009 . \quad$ [Online]. Available: https://doi.org/10.1145/1506409.1506439.

[7] S. D. Galup, J. J. Quan, R. Dattero and S. Conger,. Information technology service management: an emerging area for academic research and pedagogical development. Proceedings of the 2007 ACM SIGMIS CPR Conference on Computer Personnel Research: 
Vipul Jain, O. P. Wali and V. Raveendra Saradhi

The Global Information Technology Workforce, pp. 46-52, 2007. [Online]. Available: https://doi.org/10.1145/1235000.1235010.

[8] N. Gama, M. Vicente, and M. M. da Silva, ITIL Metamodel, ICSOC 2014, Lecture Notes in Computer Science, Vol. 8831, pp. 486-493, 2014. [Online]. Available: https://doi.org/https://doi.org/10.1007.

[9] J. Iden and T. R. Eikebrokk, "Implementing IT Service Management: A systematic literature review", International Journal of Information Management, Vol. 33, No. 3, pp. 512-523, 2013. [Online]. Available: https://doi.org/10.1016/j.ijinfomgt.2013.01.004.

[10] B. Kitchenham, "Guidelines for performing Systematic Literature Reviews in Software Engineering”, 2007.

[11] Y. Levy and T. J. Ellis, "A Systems Approach to Conduct an Effective Literature Review in Support of Information Systems Research”, Informing Science, Vol. 9, pp. 181-211, 2006. https://doi.org/10.1049/cp.2009.0961

[12] R. F. Machado, S. Reinehr and A. Malucelli, "Towards a Maturity Model for IT Service Management Applied to Small and Medium Enterprises”, pp. 157-168, 2012. [Online]. Available: https://doi.org/10.1007/978-3-642-31199-4_14

[13] M. Marrone, F. Gacenga, A. Cater-Steel and L. Kolbe, "IT Service Management: A Cross-national Study of ITIL Adoption IT Service Management: A Cross-national Study of ITIL Adoption IT Service Management: A Cross-national Study of ITIL Adoption”, Communications of the Association for Information Systems, Vol. 34, No. 49, pp. 865-892, 2014.

[14] M. Marrone and M. Hammerle, "Relevant Research Areas in IT Service Management: An Examination of Academic and Practitioner Literatures", Communications of the Association for Information Systems, Vol. 41, No. 1, pp. 517-543, 2017.

[15] M. Marrone and L. M. Kolbe, "Impact of IT Service Management Frameworks on the IT Organization”, Business and Information Systems Engineering, Vol. 3, No. 1, pp. 5-18, 2011a. [Online]. Available: https://doi.org/10.1007/s12599-010-0141-5.

[16] M. Marrone and L. M. Kolbe, "Uncovering ITIL Claims: IT Executives' Perception on Benefits and Business-IT Alignment", Information Systems and E-Business Management, Vol. 9, No. 3, pp. 363-380, 2011b. [Online]. Available: https://doi.org/10.1007/s10257010-0131-7.

[17] B. McNaughton, P. Ray and L. Lewis, "Designing an Evaluation Framework for IT Service Management", Information and Management, Vol. 47, No. 4, pp. 219-225, 2010. [Online]. Available: https://doi.org/10.1016/j.im.2010.02.003.

[18] A. L. Mesquida and A. Mas, "Integrating IT Service Management Requirements into the Organizational Management System", Computer Standards and Interfaces, Vol. 37, pp. 80-91, 2015. [Online]. Available: https://doi.org/10.1016/j.csi.2014.06.005.

[19] A. L. Mesquida, A. Mas, E. Amengual and J. A. Calvo-Manzano, "IT Service Management Process Improvement based on ISO/IEC 15504: A Systematic Review", Information and Software Technology, Vol. 54, No. 3, pp. 239-247, 2012. [Online]. Available: https://doi.org/10.1016/j.infsof.2011.11.002.

[20] S. D. Müller and C. G. de Lichtenberg, "The Culture of ITIL: Values and implementation challenges”, Information Systems Management, Vol. 35, No. 1, pp. 49-61, 2018. [Online]. Available: https://doi.org/10.1080/10580530.2017.1416946.

[21] C. Okoli and K. Schabram, "A Guide to Conducting a Systematic Literature Review of Information Systems Research", Working
Papers on Information Systems, Vol. 10, No. 26, pp. 1-51, 2010 [Online]. Available: https://doi.org/10.2139/ssrn.1954824.

[22] E. Orta and M. Ruiz, "Met4ITIL: A Process Management and Simulation-Based Method for Implementing ITIL", Computer Standards and Interfaces, 2018. [Online]. Available: https://doi.org/10.1016/j.csi.2018.01.006.

[23] E. Orta, M. Ruiz, N. Hurtado and D. Gawn, "Decision-making in IT Service Management: A Simulation Based Approach", Decision Support Systems, Vol. 66, pp. 35-51, 2014. [Online]. Available: https://doi.org/10.1016/j.dss.2014.06.002.

[24] S. Rouhani, "A Fuzzy Superiority and Inferiority Ranking Based Approach for IT Service Management Software Selection, Vol. 46, 2017.

[25] N. Shahsavarani and S. Ji, "Research in Information Technology Service Management (ITSM) (2000 - 2010)”, International Journal of Information Systems in the Service Sector, Vol. 6, No. 4, pp. 73-91, 2014. [Online]. Available: https://doi.org/10.4018/ijisss.2014100105.

[26] A. Shrestha, A. Cater-steel, M. Toleman and T. Rout,. Benefits and relevance of International Standards in a design science research project for process assessments. Computer Standards and Interfaces, pp. 0-1, April 2018. [Online]. Available: https://doi.org/10.1016/j.csi.2018.04.011.

[27] A. Shrestha, A. Cater-Steel, M. Toleman and W. G. Tan, "A Method to Select IT Service Management Processes for Improvement", Journal of Information Technology Theory and Application, Vol. 15, No. 3, pp. 31-56, 2014.

[28] C. Trusson, D. Hislop and N. F. Doherty, "The Rhetoric of "Knowledge Hoarding": A Research-Based Critique", Journal of Knowledge Management, Vol. 21, 2017. [Online]. Available: https://doi.org/10.1108/JKM-04-2017-0146.

[29] M. C. Valiente, E. García-Barriocanal and M. Á. Sicilia, “Applying Ontology-Based Models for Supporting Integrated Software Development and IT Service Management Processes”, IEEE Transactions on Systems, Man and Cybernetics: Part C Applications and Reviews, Vol. 42, No. 1, pp. 61-74, 2012. [Online]. Available: https://doi.org/10.1109/TSMCC.2011.2132717.

[30] M. C. Valiente, E. Garcia-Barriocanal and M. A. Sicilia, “Applying an Ontology Approach to IT Service Management for Business-IT Integration”, Knowledge-Based Systems, Vol. 28, pp. 76-87, 2012. [Online]. Available: https://doi.org/10.1016/j.knosys.2011.12.003.

[31] I. Vessey, V. Ramesh and R. L. Glass, "Research in Information Systems: An Empirical Study of Diversity in the Discipline and Its Journals", Journal of Management Information Systems, Vol. 19, No. 2, pp. 129-174, 2002. [Online]. Available: https://doi.org/10.1080/07421222.2002.11045721.

[32] A. Walker, T. McBride, G. Basson and R. Oakley, "ISO/IEC 15504 Measurement Applied to COBIT Process Maturity”, Benchmarking: An International Journal, Vol. 19, No. 2, pp. 159-176, 2012 [Online]. Available: https://doi.org/10.1108/14635771211224518.

[33] J. Webster and R. T. Watson, "Analyzing the Past to Prepare for the Future: Writing a Literature Review", MIS Quarterly, Vol. 26, No. 2, 2002.

[34] J. Wulf, T. J. Winkler and W. Brenner, "Measuring IT Service Management Capability: Scale Development and Empirical Validation”, 12th Int. Conf. on Wirtschaftsinformatok, pp. 630-644, 2015. 